\title{
Physical Activity Associated with HIV
}

\section{Ramírez $\mathbf{R}^{1,2}$, Ruiz $\mathbf{S}^{1,3}$ and Pedrol $E^{1,3 *}$}

${ }^{1}$ Internal Medicine Service, Hospital de Sant Pau i Santa Tecla, Tarragona, Catalonia, Spain ${ }^{2}$ Cardiovascular Risk Unit, Hospital de Sant Pau i Santa Tecla, Tarragona, Catalonia, Spain ${ }^{3}$ HIV Unit, Hospital de Sant Pau i Santa Tecla, Tarragona, Catalonia, Spain

\section{Introduction}

Sedentary behaviour, widely prevalent in developed countries is associated with a variety of diseases and with increased mortality [1]. However, physical activity clearly demonstrates beneficial effects on several health issues, including cardiovascular and all causes of mortality [2]. Among beneficial impacts of exercise we can identify a robust effect on cardiovascular outcomes inducing improvements in lipoproteins and body composition that are translated into reductions in risk of coronary disease, cardiac and probably stroke events [3], and cardiovascular deaths $[1,4]$. In this way, aerobic exercise improves insulin sensitivity, glycemic and blood pressure control, decreasing the risk of new onset diabetes, hypertension and obesity (with secondary beneficial effects). Besides this, a modest effect in prevention of breast, intestinal and pancreatic cancer [5,6] and an increment in bone mineral density (indeed reductions in hip fracture risks in patients with osteoporosis) have been established. Neurocognitive improvements (with reductions of stress, anxiety, depression and probably delays in cognitive decline and dementia development in older patients) $[7,8]$ are well known and should also be considered.

With highly active antiretroviral therapy (HAART) introduction, we have witnessed a significant increase in survival and improvement in the quality of life of HIV infected patients in developed countries [9-11]. Consequently, common disease in general population (such as cardiovascular ones) [12] and side effects related to HAART (like lipodystrophy) have become a new focus of attention in these patients. In this way, physical activity has been recommended previously in HIV to induce favourable metabolic changes and reduce risk of cardiovascular disease [13-16]. Although its prevalence is really low in this population [17], according to its low cost probably regular physical activity interventions may be cost effective in HIV infected patients [18]. Indeed, aerobic exercise or a combination of aerobic and resistance progressive exercise (at least $30 \mathrm{~min} /$ day, 3 times a week for 4 weeks) may be safe [19] and beneficial in other parameters in HIV infected patients [18], such as psychological status, quality of life, anthropometric and metabolic cardiopulmonary and immunity function. Nevertheless, effectiveness of these interventions in HIV patients has not been well established, probably due to several limitations of most of the trials that has tried to investigate this point.

The objective of this review article is to assess the possible beneficial effects of programmed exercise on HIV infected patients and the security of these interventions.

\section{Effects of Physical Activity on HIV Infected Patients}

Effects of physical activity on lipodystrophy and anthropometric parameters

Lipodystrophy, which may be present in a range of $25 \%-83 \%$ of HIV infected patients [20-22], is a stigmatizing condition that affects undoubtedly their quality of life [23-25], besides carrying an elevated cardiovascular risk.

Different guidelines on HIV people treatment $[26,27]$ and reviews about lipodystrophy management [21] mention physical exercise as an alternative in prevention and treatment of these conditions. Indeed, patients carrying out physical activity may have $79 \%$ less probability of developing lipodystrophy than patients who have a sedentary way of life [28]. Besides, few studies have evaluated its role in people infected by HIV, generally small and non prospective long term controlled trials which often did not specify the kind and intensity of exercise that may be indicated to obtain desired effects on lipodystrophy treatment. Isolated cases have reported beneficial effects $[29,30]$ in programs of physical activity program including aerobic and resistance exercises reducing abdominal fat mass in HIV patients with lipodystrophy. A small series of two and a half months aerobic and resistance exercise in HIV people with lipodystrophy [31] agreed with the cases reported before [29,30]. Anyway decreases in subcutaneous fat mass and improvements in strength and muscular mass may not be extensive to HIV lipodystrophic patients on resistance exercise alone according to few series published [15,32].

Between anthropometric parameters in HIV patients with no lipodystrophy diagnosed, most of the individual studies [21,33-35] reported no significant changes in weight between exercise and nonexercise groups. While a significant increase of $2.12 \mathrm{~kg}$ in body weight for participants in resistive exercise groups compared to a decrease of $4.5 \mathrm{~kg}$ in the non-exercising controls have been reported [36], other authors found contradictory results [16], with decreases in weight in both types of exercise. As a matter of fact a recent metanalysis including most of the previous trials [37] found no difference in change in body weight for participants in the exercise groups compared with the nonexercising control group [16,21,34-36,38].

Similarly, body composition in HIV patients who undergo exercise interventions shows contradictory results. While significant decreases in body mass index, waist-to-hip ratio, and percentage of body fat in exercisers compared with controls have been reported $[13,16,38]$, other authors found significant increases in body mass index [39] or no changes $[35,36]$ in people ongoing exercise interventions. Metanalysis mentioned before [37] demonstrated a significant decrease in percent body fat of $1.12 \%$ ( $95 \%$ CI: $-2.18,-0.07, \mathrm{n}=119, P=0.04)$ for participants in the aerobic exercise group compared with participants in the non-exercising control group with no differences in change in waist circumference; hip circumference and waist-to-hip ratio. No difference in the change in body mass index for patients enrolled in the aerobic

*Corresponding author: E. Pedrol, HIV Unit, Internal Medicine Service, Hospita de Sant Pau i Santa Tecla, Rambla Vella, 14, Tarragona-43003, Catalonia, Spain Tel: 34977259 900; E-mail: epedrol@xarxatecla.cat

Received December 01, 2011; Accepted March 22, 2012; Published March 25 2012

Citation: Ramírez R, Ruiz S, Pedrol E (2012) Physical Activity Associated with HIV. J AIDS Clinic Res S9:001. doi:10.4172/2155-6113.S9-001

Copyright: (c) 2012 Ramírez R, et al. This is an open-access article distributed under the terms of the Creative Commons Attribution License, which permits unrestricted use, distribution, and reproduction in any medium, provided the original author and source are credited. 
exercise group compared with participants in the non-exercising control group was reported [37].

In studies which assessed muscle strength, most of them have reported improvements among exercisers compared with nonexercisers $[21,34-36,39,40]$.

Consequently body fat mass is probably reduced with aerobic exercise in HIV infected patients and this effect may be extended to those with lipodystrophy. While there is quite possibly a beneficial effect on muscle strength of HIV patients, other anthropometric parameters such as weight or waist to hip ratio show inconclusive results to date.

\section{Effects of physical activity on metabolic parameters}

Several epidemiological studies in persons without HIV infection demonstrate that a high fitness level offers protection against cardiovascular diseases and premature mortality [41]. Morphological (lipodystrophy -see before) and metabolic abnormalities (including insulin resistance, dyslipidaemia and low-grade inflammation) associated, particularly with HAART, may contribute to an increased risk of cardiovascular diseases in HIV-infected patients.

Endurance training alone or combined with strength training decreases trunk and visceral fat in HIV-infected with lipodystrophy $[36,42]$. Both strength and endurance training improve peripheral insulin sensitivity in human immunodeficiency virus-infected patients with lipodystrophy [15], similar to HIV-negative individuals [43]. These studies $[15,42]$ also demonstrate beneficial effects on lipid profiles on decreased total cholesterol, LDL-cholesterol, free fatty acids and HDLcholesterol increased after endurance training, whereas triglycerides and free fatty acids decreased and HDL-cholesterol increased after strength trainings. Probably short term exercise interventions are able to produce significant reductions in lipid profile $[32,44]$, preferably on hypertriglyceridemia [44], in HIV-infected men treated with HAART. A recent study from Brazil [18] suggests that the practice of regular exercise in individuals with HIV infection promoted significant modifications in body fat and hip circumference, increasing muscle mass and reducing fasting glucose and risk of diabetes. The authors also detected a decrease in low-density lipoprotein cholesterol and triglycerides. In conclusion regular exercising in HIV infected patients significantly improves the metabolic parameters.

\section{Immunological and virological effect of physical activity}

Results of individual studies have found significant differences in CD4 counts of HIV infected patients in exercise groups compared with controls $[36,39,45,46]$. Indeed considerable averages of increment in CD4 count $\left(60\right.$ cells $/ \mathrm{mm}^{3}$ [39] and 38 cells $/ \mathrm{mm}^{3}$ [46]) compared to a sensible decrease (39 cells $/ \mathrm{mm}^{3}$ [39] and 61 cells $/ \mathrm{mm}^{3}$ [46]) have been found. Less significant increments have been shown by other authors $[36,45]$ in the exercise groups with averages of decrease of 78 and 4 cells $/ \mathrm{mm}^{3}$ in control groups. Nevertheless these results are inconclusive, attending to non significant changes or increases statistically nonsignificant that have been reported by others $[13,21,33-35,38,40,47,48]$.

A recent metanalysis that included most of the mentioned trials, found no difference in change in CD4 count for participants in the exercise intervention group compared with the non-exercising control group [37]. Although this metanalysis may be quite heterogeneous because included trials comparing more versus less intensive aerobic exercise, aerobic exercise against no other intervention, aerobic exercise and another intervention such as metformin [34] or lipid lowering diet [16] against aerobic exercise alone...) a significant trend towards an improvement in CD4 count of 69.58 cells $/ \mathrm{mm}^{3}$ for subanalysis exclusively of participants in the aerobic exercise trials compared with the non-exercising controls [37] was found. Besides that, the cutoff point estimated was above 50 cells $/ \mathrm{mm}^{3}$, which suggests a potential clinically important increase in $\mathrm{CD} 4$ count for interval exercisers compared with non-exercisers.

On the other side, individual results have found non significant averages of decrease in viral load [47] in the exercise groups compared to no exercising controls, although co-interventions of exercise alone or with low lipid diet has been traduced on significant viral load values below 80 copies $/ \mathrm{mL}$ [16]. No significant increase in viral load in people who underwent an exercise [35,38], program, or no differences in viral load $[21,34]$ with respect to those who did not perform physical activity has not been reported either.

Consequently it is quite improbable the existence of a significant difference in the change of viral load for participants in the exercise intervention groups compared with the non-exercising controls, independently being aerobic or aerobic combined with resistance exercise [37].

\section{Cardiopulmonary effects of physical activity}

Individual studies that measured cardiopulmonary status reported significant improvements in cardiopulmonary outcomes in exercisers versus non exercising controls. In this way significant improvements in maximum oxygen consumption (VO2max) [39,47], lactic acid threshold [47], and significant reductions in maximum heart rate $[36,40]$ could be developed in people undergoing physical activity.

Aerobic exercise intervention groups can result in the most significant improvements in cardiopulmonary function, reaching changes in $\mathrm{VO} 2 \mathrm{max}$ greater than $2 \mathrm{~mL} / \mathrm{kg} / \mathrm{min}$, compared with the non-exercising controls [37]. Indeed a significant trend towards a greater improvement in VO2max of $4.30 \mathrm{~mL} / \mathrm{kg} / \mathrm{min}$ for participants in heavy-intensity exercise groups compared with the moderate-intensity exercise group has been reported [37]. These results suggest a potential clinically important improvement in cardiopulmonary function in aerobic HIV exercisers.

\section{Psychological effects of physical activity}

Probably there is a significant improvement in the depression subscale of Profile of Mood States Scale (POMS) for participants in the exercise intervention group compared with the non-exercising control group [37]. Significant reduction of 7.68 points on physical active groups represents a clinically important improvement in depressiondejection among exercisers compared to non-exercisers.

No significant differences between the moderate-and high-intensity exercise groups for depression [39] or general health status [33,45] have been reported. Nevertheless, isolated authors have found significant improvements in general health [48] and quality of life questionnaire (QOL) $[13,47]$ among exercisers, with lower levels of depression $[38,46]$ and anxiety [46], higher mood and life satisfaction [36] and unspecified beneficial effects in psychological status $[36,49,50]$.

According to these results it is quite possible that exercise (aerobic and maybe resistance activities as well) could give a beneficial outcome in psychological status in adults with HIV.

\section{Other effects of physical activity on HIV infected patients}

Effects on bone mineral metabolism: Accelerated bone mineral loss in HIV infected patients receiving potent antiretroviral therapy 
is clearly established [51], although it is probably that a short-term accelerated bone mineral loss develops in cohorts initiating HAART, probably followed by a longer period of stability [52]. Besides that, the difference in bone mineral density between HIV positive and HIV negative people may disappear after adjustment for weight [53]. Decreases in bone mineral density may increase fracture risk in HIV infected people [54]. In this way, it is quite possible that strength training reduces bone loss in HIV-infected patients, the same as happens in non HIV infected people. As a matter of fact, maintaining adequate weight and engaging in physical activity has been reported as a strategy that may help to preserve and perhaps improve bone mass density in HIVinfected patients [55].

In this way, thirty minutes of exercise (including jogging or walking) at least 3 days a week has been recently recommended [56] as a useful measure to prevent osteoporosis in HIV people. Nevertheless non double blind randomized controlled trials of exercise effects preventing osteoporosis in HIV infected patients have been performed.

Effects on cancer: The modest effect in prevention on several cancer $[5,6]$ demonstrated by exercise interventions, and the probable reduction of all cancer mortality demonstrated in prospective studies in non HIV [57] people has not been investigated as far as we know in HIV infected people.

\section{Security of Physical Activity on HIV Infected Patients}

Probable exercise interventions in HIV people are as safe as they are in general population. No adverse events or side effects [21], and no withdrawal signs due to illness or infection $[38,47]$ has been mentioned in previous reports. As a matter of fact, a review considering joints, muscular, bone, nervous, vascular or immunity (decline in CD4 cell count or progression to AIDS) outcomes, as well as hospitalizations or deaths show no adverse effects in HIV infected patients who underwent exercise interventions [37]. Certainly, the only isolated adverse events related to exercise interventions reported before were an asthma exacerbation [35], a hospitalization [39] and a death case [40] (the latter, not attributed to the exercise intervention). According to this evidence, there is probably no formal contraindication in HIV patients as regards ongoing exercise activities.

\section{Limitations}

Conclusions about the effect of exercise interventions in HIV infected patients are limited to few small trials that investigated this aim. Investigations have been performed predominately in men within a close range of ages [37], but a wide range of HIV infected patients (lipodystrophic and non-lipodystrophic, on HAART and untreated...). An important limitation too is the high rate of withdrawal in the trials [37], more than $25 \%$ in some of them. Besides that, several times intervention groups included a co-intervention, such as exercise and diet $[16,29]$ or exercise and metformin [34], which makes difficult clarification of exercise effects alone. Body composition at the beginning of the trials has not always been reported, and the specification of the type of exercise and the level of supervision of this activity is infrequent. Consequently the above conclusions should be interpreted with caution.

\section{Conclusions}

Progressive exercise interventions (aerobic and maybe resistance interventions too) report beneficial effects on outcomes in psychological status in HIV infected adults. There is quite possibly a benefit in muscle strength, body fat distribution and cardiopulmonary function (preferably with aerobic exercise), as well as better parameters of lipid profile and insulin sensitivity compared with non exercising HIV people. These interventions are safe, probably with no change in viral load or CD4 count (or with little increase of these cells in HIV people ongoing aerobic exercise), and probably cost effective. In conclusion regular exercise should be extensively recommended in HIV infected people with no other general contraindication.

Future investigations should clarify possible differences between sexes or ethnics in order to standardize recommendations. Probably bigger trials with intention to treat analysis will collaborate to solve the problem of frequent withdrawals and the difficulty to obtain certain results.

\section{References}

1. Proper KI, Singh AS, van Mechelen W, Chinapaw MJ (2011) Sedentary behaviors and health outcomes among adults: a systematic review of prospective studies. Am J Prev Med 40: 174-182.

2. Kodama S, Saito K, Tanaka S, Maki M, Yachi Y, et al. (2009) Cardiorespiratory fitness as a quantitative predictor of all cause mortality and cardiovascular events in healthy men and women: a meta-analysis. JAMA 301: 2024-2035.

3. Wendel-Vos GC, Schuit AJ, Feskens EJ, Boshuizen HC, Verschuren WM, et al (2004) Physical activity and stroke. A meta-analysis of observational data. Int J Epidemiol 33: 787-798.

4. Yusuf S, Hawken S, Ounpuu S, Dans T, Avezum A, et al. (2004) Effect of potentially modificable risk factors associated with myocardial infarction in 52 countries (the INTERHEART study): case-control study. Lancet 364: 937-952.

5. Michaud DS, Giovannucci E, Willett WC, Colditz GA, Stampfer MJ, et al. (2001) Physical activity, obesity, height, and the risk of pancreatic cancer. JAMA 286: 921-929.

6. Meyerhardt JA, Giovanucci EL, Ogino S, Kirkner GJ, Chan AT, et al. (2009) Physical activity and male colorectal cancer survival. Arch Intern Med 169: 2102-2108.

7. Herring MP, O'Conner PJ, Dishman RK (2010) The effect of exercise training on anxiety symptoms among patients: a systematic review. Arch Intern Med 170: $321-331$.

8. Martin CK, Church TS, Thompson AM, Earnest CP, Blair SN (2009) Exercise dose and quality of life: a randomized controlled trial. Arch Intern Med 169: 269- 278.

9. Palella FJ Jr, Delaney KM, Moorman AC, Loveless MO, Fuhrer J, et al. (1998) Declining morbidity and mortality among patients with advanced human immunodeficiency virus infection. HIV Outpatient Study Investigators. N Engl J Med 338: 853-860.

10. Crum NF, Riffemburg RH, Wegner S, Agan BK, Tasker SA, et al. (2006) Comparisons of causes of death and mortality rates among HIV-infected persons: analysis of the pre-, early, and late HAART (highly active antiretroviral therapy) eras. J Acquir Immune Defic Syndr 41: 194-200.

11. Sterne JA, Hernán MA, Ledergerber B, Tilling K, Weber R, et al. (2005) Longterm effectiveness of potent antiretroviral therapy in preventing AIDS and death: a prospective cohort study. Lancet 366: 378-384.

12. Friis-Møller N, Sabin CA, Weber R, d'Arminio Monforte A, El-Sadr WM, et al (2003) Combination antiretroviral therapy and the risk of myocardial infarction. N Engl J Med 349: 1993-2003.

13. Mutimura E, Stewart A, Crowther NJ, Yarasheski KE, Cade WT (2008) The effects of exercise training on quality of life in HAART-treated HIV-positive Rwandan subjects with body fat redistribution. Qual Life Res 17: 377-385.

14. Robinson FP, Quinn LT, Rimmer JH (2007) Effects of high-intensity endurance and resistance exercise on HIV metabolic abnormalities: a pilot study. Biol Res Nurs 8: 177-185

15. Lindegaard B, Hansen T, Hvid T, van Hall G, Plomgaard P, et al. (2008) The effect of strength and endurance training on insulin sensitivity and fat distribution in human immunodeficiency virus-infected patients with lipodystrophy. J Clin Endocrinol Metab 93: 3860-3869.

16. Terry L, Sprinz E, Stein R, Medeiros NB, Oliveira J, et al. (2006) Exercise training in HIV-1-infected individuals with dyslipidemia and lipodystrophy. Med Sci Sports Exerc 38: 411-417. 
17. Barros CR, Zuchhi EM, Franca Junior I (2010) Physical activity level among children and adolescents orphaned by AIDS. Rev Bras Epidemiol 13: 446-456.

18. Ogalha C, Luz E, Sampaio E, Souza R, Zarife A, et al. (2011) A Randomized, Clinical Trial to Evaluate the Impact of Regular Physical Activity on the Quality of Life, Body Morphology and Metabolic Parameters of Patients With AIDS in Salvador, Brazil. J Acquir Immune Defic Syndr 57: S179-185.

19. O'Brien K, Nixon S, Tynan AM, Glazier RH (2008)Aerobic exercise interventions for people living with HIV/AIDS: Implications for practice, education and research. Physiother Can 58: 114-129.

20. Miller J, Carr A, Emery S, Law M, Mallal S, et al. (2003) HIV lipodistrophy: prevalence, severity and correlates of risk in Australia. HIV Med 4: 293-301.

21. Grinspoon S, Carr A (2005) Cardiovascular risk and body-fat abnormalities in HIV-infected adults. N Engl J Med 352: 48-62.

22. Friis-Møller N, Weber R, Reiss P, Thiébaut R, Kirk O, et al. (2003) Cardiovascular disease risk factors in HIV patients-association with antiretroviral therapy. Results from the DAD study. AIDS 17: 1179-1193.

23. Collins E, Wagner C, Walmsley S (2000) Psychological impact of lipodystrophy syndrome in HIV infection. AIDS Read 10: 546-550.

24. Martínez E, García-Viejo MA, Blanch L, Gatell JM (2001) Lipodystrophy syndrome in patients with HIV infection: quality of life issues. Drug Saf 24: 157-166

25. Blanch J, Rousaud A, Martínez E, De Lazzari E, Peri JM, et al. (2002) Impact of lipodystrophy on the quality of life of HIV-1-infected patients. J Acquir Inmmune Defic Syndr 31: 404-407.

26. European AIDS Clinical Society. Version 6.0 October 2011.

27. (2011) National consensus document by GESIDA/National Aids Plan on antiretroviral treatment in adults infected by the human immunodeficiency virus (January 2011 update). Enferm Infecc Microbiol Clin 29: 209.e1-103.

28. Segatto AF, Freitas Junior IF, Santos VR, Alves KC, Barbosa DA, et al. (2011) Lipodystrophy in HIVIAIDS patients with different levels of physical activity while on antiretroviral therapy. Rev Soc Bras Med Trop 44: 420-424.

29. Roubenoff R, Schmitz H, Bairos L, Layne J, Potts E, et al. (2002) Reduction of abdominal obesity in lipodystrophy associated with human immunodeficiency virus infection by means of diet and exercise: Case report and Proof of Principle. Clin Infec Dis 34: 390-393.

30. Mendes EL, Ribeiro Andaki AC, Brito CJ, Cordova C, Natali AJ, et al. (2011) Beneficial effects of physical activity in an HIV-infected woman with lipodystrophy: a case report. J Med Case Reports 5: 430

31. Jones SP, Doran DA, Leatt PB, Maher B, Pirmohamed M (2001) Short-term exercise training improves body composition and hyperlipidaemia in HIVpositive individuals with lipodystrophy. AIDS 15: 2049-2051.

32. Souza PM, Jacob-Filho W, Santarem JM, Silva AR, Li HY, et al. (2008) Progressive resistance training in elderly HIV-positive patients: does it work? Clinics (Sao Paulo) 63: 619-624

33. Terry L, Sprinz E, Ribeiro JP (1999) Moderate and High Intensity Exercise Training in HIV-1 Seropositive Individuals: a Randomized Trial. Int J Sports Med 20: 142-146.

34. Driscoll SD, Meininger GE, Lareau MT, Dolan SE, Killilea KM, et al. (2004) Effects of exercise training and metformin on body composition and cardiovascular indices in HIV-infected patients. AIDS 18: 465-473.

35. Dolan SE, Frontera W, Librizzi J, Ljungquist K, Juan S, et al. (2006) Effects of a supervised home-based aerobic and progressive resistance training regimen in women infected with human immunodeficiency virus: a randomized trial. Arch Intern Med 166: 1225-1231.

36. Lox CL, McAuley E, Tucker RS (1996) Aerobic and resistance exercise training effects on body composition, muscular strength, and cardiovascular fitness in an HIV-1 population. Int J Behav Med 3: 55-69,

37. O'Brien K, Nixon S, Tynan AM, Glazier R (2010) Aerobic exercise interventions for adults living with HIVIAIDS. Cochrane Database Syst Rev 4: CD001796.

38. Smith BA, Neidig JL, Nickel JT, Mitchell GL, Para MF, et al. (2001) Aerobic exercise: effects on parameters related to fatigue, dyspnea, weight and body composition in HIV-infected adults. AIDS 15: 693-701.

39. Perna FM, LaPerriere A, Klimas N, Ironson G, Perry A, et al. (1999) Cardiopulmonary and $\mathrm{CD} 4$ cell changes in response to exercise training in early symptomatic HIV infection. Med Sci Sports Exerc 31: 973-979.

40. Rigsby LW, Dishman RK, Jackson AW, Maclean GS, Raven PB (1992) Effects of exercise training on men seropositive for the human immunodeficiency virus-1. Med Sci Sports Exerc 24: 6-12.

41. Blair SN, Cheng Y, Holder JS (2001) Is physical activity or physical fitness more important in defining health benefits? Med Sci Sports Exerc 33: S379-399.

42. Thoni GH, Fedou C, Brun JF, Fabre J, Renard E, et al. (2002) Reduction of fat accumulation and lipid disorders by individualized light aerobic training in human immunodeficiency virus infected patients with lipodystrophy and/or dyslipidemia. Diabetes Metab 28: 397-404.

43. Snowling NJ, Hopkins WG (2006) Effects of different models of exercise training on glucose control and risk factors for complications in type 2 diabetic patients: a meta-analysis. Diabetes Care 29: 2518-2527.

44. Yarasheki KE, Tebas P, Stanerson B, Claxton S, Marin D, et al. (2001) Resistance exercise training reduces hypertriglyceridemia in HIV-infected men treated with antiviral therapy. J Appl Physiol 90: 133-138.

45. Baigis J, Korniewicz DM, Chase G, Butz A, Jacobson D, et al. (2002) Effectiveness of a home-based exercise intervention for HIV infected adults: a randomized trial. J Assoc Nurses AIDS Care 13: 33-45.

46. LaPerriere AR, Antoni MH, Schneiderman N, Ironson G, Klimas N, et al. (1990) Exercise Intervention Attenuates Emotional Distress and Natural Killer Cell Decrements Following Notification of Positive Serologic Status for HIV-1. Bio feedback Self Regul 15: 229-242.

47. Stringer WW, Berezovskaya M, O'Brien WA, Beck CK, Casaburi R (1998) The effect of exercise training on aerobic fitness, immune indices, and quality of life in HIV+ patients. Med Sci Sports Exerc 30: 11-16.

48. MacArthur RD, Levine SD, Birk TJ (1993) Supervised exercise training improves cardiopulmonary fitness in HIV-infected persons. Med Sci Sports Exerc 25: 684-688.

49. Bhasin S, Storer TW, Javanbakht M, Berman N, Yarasheski KE, et al. (2000) Testosterone replacement and resistance exercise in HIV-infected men with weight loss and low testosterone levels. JAMA 283: 763-770.

50. Agin D, Gallagher D, Wang J, Heymsfield SB, Pierson RN Jr, et al. (2001) Effects of whey protein and resistance exercise on body cell mass, muscle strength, and quality of life in women with HIV. AIDS 15: 2431-2440

51. Tebas P, Powderly WG, Claxton S, Marin D, Tantisiriwat W, et al. (2000) Accelerated bone mineral loss in HIV-infected patients receiving potent antiretroviral therapy. AIDS 14: F63-67.

52. Bolland MJ, Wang TK, Grey A, Gamble GD, Reid IR (2011) Stable bone density in HAART-treated individuals with HIV: a meta-analysis. J Clin Endocrinol Metab 96: 2721-2731.

53. Bolland MJ, Grey AB, Gamble GD, Reid IR (2007) Clinical review: low body weight mediates the relationship between HIV infection and low bone mineral density: a meta-analysis. J Clin Endocrinol Metab 92: 4522-4528.

54. Arnsten JH, Freeman R, Howard AA, Floris-Moore M, Lo Y, et al. (2007) Decreased bone mineral density and increased fracture risk in aging men with or at risk for HIV infection. AIDS 21: 617-623.

55. Jacobson DL, Spiegelman D, Knox TK, Wilson IB (2008) Evolution and Predictors of Change in Total Bone Mineral Density Over Time in HIV-Infected Men and Women in the Nutrition for Healthy Living Study. J Acquir Immune Defic Syndr 49: 298-308.

56. McComsey GA, Tebas P, Shane E, Yin MT, Overton ET, et al. (2010) Bone Disease in HIV Infection: A Practical Review and Recommendations for HIV Care Providers. Clin Infect Dis 51: 937-946.

57. Wen CP, Wai JP, Tsai MK, Yang YC, Cheng TY, et al. (2011) Minimum amount of physical activity for reduced mortality and extended life expectancy: a prospective cohort study. Lancet 378: 1244-1253. 